\title{
Public Health Residency Training
}

\author{
By S. P. LEHMAN, M.D., M.P.H., and D. R. PETERSON, M.D.
}

"I DIDN'T KNOW there was such a thing." We have heard this statement repeatedly from intern and practicing physician alike. The "thing" they refer to is the residency program in public health. While residencies in clinical specialties are well known and accepted, such is not the case in the field of public health. Perhaps this is because the specialty is only about 8 years old. By June 30,1956 , only 1,684 certificates had been awarded in public health.

Residencies for physicians interested in public health as a specialty have evolved since the incorporation of the American Board of Preventive Medicine and Public Health in 1948. The board was formed on the recommendation of a joint committee of the American Medical Association and of the American Public Health Association. It was created in accordance with action of the Advisory Board for the Medical Specialties and was recognized and approved as a medical specialty board by the Council on Medical Education and Hospitals of the American Medical Association in 1949 (1). The purpose of the board is twofold:

- To encourage the study, improve the practice, elevate the standards, and advance the cause of preventive medicine.

- To grant and issue to physicians, duly licensed by law to practice medicine, certificates of special knowledge in the various fields of preventive medicine. The fields in which certification is granted are public health, aviation medicine, and occupational medicine.

Dr. Lehman and Dr. Peterson are with the Seattle. King County Department of Public Health, Seattle, Wash. Dr. Lehman is director of the department, and Dr. Peterson, a former public health resident with the department, is a district health officer.
To be eligible for examination by the American Board of Preventive Medicine, candidates must meet certain general requirements. These pertain to character, professional demeanor, medical education, internship, and medical licensure. Additional requirements for public health candidates are:

1. Successful completion (after internship) of at least 1 academic year of graduate study leading to the degree of master of public health or an equivalent degree or diploma; or training or study decreed by the board to be substantially equivalent to such graduate study.

2. Residency (after internship) of at least 2 years of field experience in general public health practice, which includes planned instruction, observation, and active participation in a comprehensive, organized public health program, 1 year of which may be an approved clinical residency in a field directly related to public health.

3. A period (after internship) of not less than 3 years, in addition to 1 and 2 above, of special training in, or teaching or practice of, public health.

4. Limitation of practice to full-time teaching or practice of public health as a specialty.

In 1955-56 the Residency Review Committee for Preventive Medicine and Public Health (Q) had approved residency programs for 2 years of field training in 15 States (see map). In 12 States, 35 local areas were designated as satisfactory for field training ; 2 were approved on a statewide basis; and 1 was given provisional approval.

'Through a questionnaire sent in September 1956 to all the States known to have a program, we learned that 42 residents had been trained since $1950 ; 26$, or 62 percent, of these residents were doing full-time public health work. Sixty-three appointments were available, but only 19 (30 percent) were filled (see table). 
The picture was similar in 1954-55, when only 26 ( 37 percent) of the 71 available appointments were filled: 21 of the 65 first-year appointments available and 5 of the 6 second-year appointments.

Why so small a percentage of the available residencies are filled is inexplicable. Perhaps too few physicians have been told about the program.

\section{Seattle-King County Program}

The Seattle-King County Department of Public Health in Washington has sponsored a residency program in public health since 1952. Our experiences may be of interest to the profession at large as well as to those who are personally involved in postgraduate medical education.

The program adopted by the Seattle-King County Department of Public Health in 1952 began with one resident who, quite literally, had to "play by ear." After completing 1 or 2 months' time in a given service, he selected another for his next assignment. His notes and special studies helped the department to correct some of the deficiencies of the program and to see where the resident would profit by additional supervision or advice. The lack of a basic curriculum was perhaps the worst fault of the first year.

A second candidate, accepted in 1953, left for a residency in surgery before he had finished training. Perhaps we erred in not scrutinizing the intentions and qualifications of the applicant with sufficient care.

\section{States with residencies in public health and pre-} ventive medicine, 81 positions, 1956.

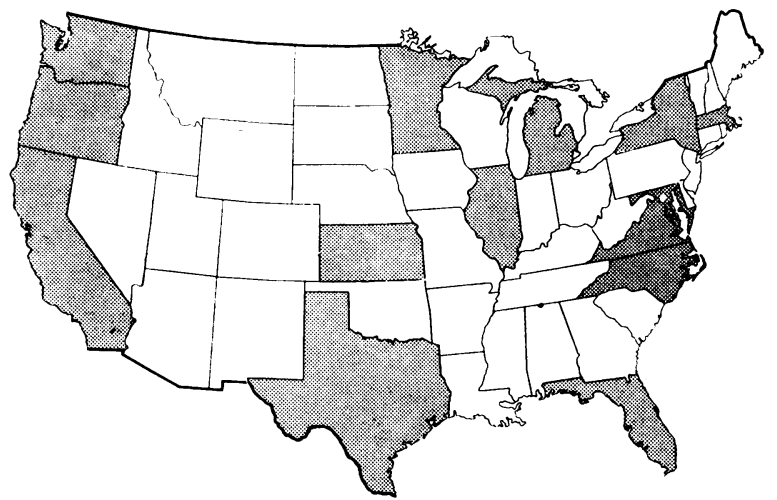

Two residents were accepted for 1954. Their work together in activities that consisted mostly of observation and study enabled them to talk over the experiences of the day, make plans for the next week's program, and, when necessary, bolster one another's morale. A schedule assured their spending a definite period of time in each service. During the remainder of the year, the residents were assigned to a district office where they assumed responsibility gradually as their experience and knowledge accumulated. This arrangement proved so satisfactory that two additional residents were accepted in 1955 .

\section{Curriculum}

The men who have participated in our program as residents have come to us from the hectic and demanding routines of internship or private practice where they were preoccupied with problems of individual patients. To change their professional frame of reference so that they see an entire community as their patient requires time, study, and some degree of personal reorientation as well as specific instruction in technical disciplines. Therefore, the resident's curriculum is designed to present fundamental disciplines of preventive medicine and public health during the first 6 months. At the same time it is sufficiently flexible and leisurely to enable the resident to take advantage of training opportunities that may arise outside the health department, such as special courses at the University of Washington or those sponsored by other agencies, public health meetings, and conferences with visiting experts.

Our curriculum consists of the following four basic subjects :

$\begin{array}{lr}\text { Public health administration } & \text { Months } \\ \text { Community resources } & \\ \text { Preventive medicine } & \\ \text { Environmental sanitation }\end{array}$

\section{Public Health Administration}

From the beginning, the director of public health has supervised the residents during their first 2 months in the health department. $\mathrm{No}$ one is in a better position to introduce the resi- 
dents to the health department personnel, to the community, and to the history, resources, and peculiarities of the area in which they will work.

From the vantage point of the director's office, the residents see the whole operation, though they are not necessarily expected to understand the significance of all that they see during this first exposure. They are included in staff conferences, committee meetings, discussions of personnel problems, hearings before the city council, and discussions of proposed ordinances and other related business of the department, with the anticipation that they will catch the "sense" of what is going on. Interstaff committee work, writing assignments, helping with correspondence, and similar activities of routine office management help them relate to the organization and feel that they are on the team from the start.

\section{Community Resources}

Knowing the community is to the public health physician what knowing anatomy is to the surgeon. Here again the director, with his experience and knowledge, can point out the more important community resources within his jurisdiction. The residents then take the initiative in visiting as many of these organizations as time permits. Among these organizations are other official public health agencies, various volunteer health organizations, industrial medical departments, prepaid medical service organizations, hospitals, group practice clinics, the juvenile court with its satellite service groups, jails, a screening-examination center, and medical rehabilitation facilities. Other governmental organizations, Federal, State, and local, complete the itinerary.

\section{Preventive Medicine}

The preventive medicine portion of the curriculum represents more or less familiar ground to the residents and offers them an opportunity to exercise some of the talents developed by their hard-won medical education and experience.

Approximately 3 weeks are devoted to tuberculosis control. Under supervision, trainees participate in outpatient clinics and review the
Status of appointments in 14 public health residency programs, 1956

\begin{tabular}{r|r|r|r}
\hline Appointments & $\begin{array}{c}\text { Number } \\
\text { avail- } \\
\text { able }\end{array}$ & \multicolumn{2}{|c}{ Filled } \\
\cline { 2 - 3 } & & Number & Percent \\
\hline Total & 63 & 19 & 30 \\
1st year. & 35 & 7 & 20 \\
2d year. . & 28 & 12 & 45
\end{tabular}

miniature films taken by the various mobile X-ray units. They accompany the State tuberculosis control officer, or his deputies, to other health departments to observe the conduct of outlying clinics and consultations. They are invited to staff meetings at the sanatoriums and are urged to attend whatever professional meetings are being held at the time.

Well-child clinics are held throughout the local health department's jurisdiction. The residents are expected to staff some of these clinics and to familiarize themselves with the type of service offered. Special projects and courses have been devised to help them comprehend the concepts of child health and the significance of morbidity and mortality statistics. Programs for crippled children, for sight and hearing conservation, and for medical care for children are included in their assignments. They are also urged to attend the clinical presentations at the University of Washington or the Children's Orthopedic Hospital and to study the operation of the newly formed poison control center.

Through worn shoe leather and perseverance the aspiring health physician learns the elements of communicable disease control and epidemiology, for he is asked to assume responsibility for making appropriate investigations when indicated. The facilities of all the hospitals that accept communicable disease cases are available in the event of an unusual or interesting case or outbreak. Practical problems of disease reporting, levels of community immunizations, cooperation with other official departments, control regulations and their enforcement, to mention only a few, point up some of the challenges of this aspect of preventive medicine to the residents.

The special case of venereal disease control 
offers the resident insight into the productive teamwork of the astute clinician and the special investigator. The unique records (example: nickname file), the conduct of the clinic, the examination of patients, the special training of the investigators, and the occasional positive dark field examination are some of the highlights of this service.

\section{Environmental Sanitation}

A large departmentalized sanitation division affords the residents ample opportunity to see this aspect of public health practice at first hand with a well-qualified person to instruct them. A typical experience in the milk section, for an example, includes an early morning briefing in the main office, followed by a visit to the farm, milk receiving plant, milk processing plant, and then, perhaps, to the laboratory to witness the elucidation of a consumer complaint. Technical factors influencing grade, control of pasteurizing equipment, public relations with milk producers, and a host of other problems are explained. To illustrate the geographic differences in the program, the resident is taken to several areas in this milkshed, which literally surrounds the entire Puget Sound.

This same general type of instruction is given in the other sections: general sanitation, meat, plumbing, plague and vermin control, sewerage installations, and water works. It is in the sanitation division that the resident gets a better view of public health work at its grass roots level than anywhere else.

\section{Completion of Training}

Following his indoctrination, the resident is assigned to one of three district health offices situated strategically on the periphery of the metropolitan area. Each district health office serves both a rural and an urban population, with public health problems which are, we feel, representative of those he might expect to meet in the future.

He can confer with experienced personnel on any problem that he feels he cannot solve by himself. Moreover, since his tenure in this post is about 21 months, he has sufficient opportunity to become established in the community and to learn the elements of public relations which, in our area at present, involve participation with local health councils, municipal organizations of many descriptions, school personnel, radio and newspaper representatives, and similar groups. As often as is practical and within budgetary limitations, this resident, now a district health officer, is encouraged to attend both local and national meetings of public health workers in order that he may better identify himself with this group of medical specialists.

After some 27 months with this health department, the resident attends a school of public health of his own choosing. While at school he is given a monthly stipend as well as tuition and travel funds. When he has completed his academic work and received the master of public health degree, or its equivalent, the resident has fulfilled the formal training requirements of the American Board of Preventive Medicine.

\section{Comments}

Inherent in a residency program are features that benefit both resident and health department. How these are integrated into the operation to maintain an equitable balance between values received by each is shown in the inset.

We have been fortunate in getting physician applicants with varied backgrounds. Two had worked in health departments previously, one as a sanitarian and the other as a statistician. Others have come directly from internship, from military service, or from private practice. These men have been intent on making public health a career. Like their counterparts in the clinical specialties, they hope to become accredited specialists in their chosen field. They anticipate training that will enable them to act as consultants to physician and layman alike in medical matters that pertain to the community. The excellent scholastic records of our residents who have matriculated in schools of public health attest to the seriousness of their intentions. We like to feel that careful selection of candidates and broad practical field training contribute to this achievement.

After basic orientation each resident sets his own pace in assuming responsibility for clinics, programs, and planning. However, 


\section{Balance in Benefits}

\section{Resident Health Department}

AMA-approved postgraduate training Increasing responsibility and status

Contact with professional colleagues

Reasonable salary for family maintenance Association with University Medical School Modest research activity and special projects
Stable, well-trained medical staff

Relief of regular staff (members)

Improved relations with doctors and hospitals Just compensation for service

Recruitment and teaching responsibilities met

Results of research sometimes applicable competent advice is no farther away than the telephone. At a time when the resident's convictions concerning his chosen specialty may be conditional, supervision of this nature mitigates against discouraging mistakes without suppressing initiative. As the resident's capabilities become apparent, responsibility can be delegated in areas that will relieve some of the regular staff.

The resident must become a part of his community and win the confidence of his professional colleagues in that community. $\mathrm{He}$ is encouraged to join the medical society and other organizations relevant to his position as district health officer. This representation personalizes the health department on a district level and brings its programs closer to the communities for which they are intended.

Our initial stipend is $\$ 500$ per month the first year. The resident through his work in clinics, immunization programs, and other activities actually earns his stipend as much as the hospital resident who performs as house physician. Consistent with increasing responsibility and ability, the stipend is raised to $\$ 800$ per month the second year.

Each resident is appointed assistant clinical instructor in public health at the University of Washington Medical School. In this capacity he is expected to assist in teaching public health to medical students and to participate in special seminars and courses, all of which help to fix concepts and material in his mind that he has only recently learned himself. If, by precept or example, a student is encouraged to choose public health as a career, the resident contributes to recruitment of personnel.

Project activity in our residency program has been both diverse and productive. Residents have contributed significantly to the following: civil defense and disaster preparedness program; publication of a public health reference manual for physicians; poliomyelitis survey; poliomyelitis immunization program; district office administration; investigation of a multiple-puncture tuberculin test (Heaf test); medical consultation for State vocational rehabilitation division.

We have been asked whether a physician with public health experience but without formal training should undertake a residency such as ours. We cannot answer this question categorically, for some physicians have been interested in the orientation part of our program. Certainly a new staff member could profit from thorough orientation to our community and the department. However, our program is primarily designed for training the uninitiated physician in the disciplines he will find essential to his pursuit of a career in public health.

\section{REFERENCES}

(1) Certification of specialists in public health, aviation medicine, and occupational medicine. Ed. 4. Bull. American Board of Preventive Medicine. Baltimore, $\mathbf{1 9 5 5}$.

(2) Approved residencies and fellowships. 21. Preventive medicine and public health. J. A. M. A. 162 : 364, Sept. 22, 1956. 